\title{
CRESCIMENTO RADICULAR E NUTRIÇÃO DA SOJ A CULTIVADA NO SISTEMA PLANTIO DIRETO EM RESPOSTA AO CALCÁRIO E GESSO NA SUPERFÍCIE(1)
}

\author{
E. F. CAIRES $S^{(2)}$, A. F. FONSECA(3), I. C. FELDHAUS ${ }^{(4)} \& J$. BLUM $^{(4)}$
}

\begin{abstract}
RESUMO
A deficiência de cálcio e a toxidez de alumínio têm sido os fatores de acidez mais limitantes ao cresci mento de raízes. Com o objetivo de avaliar o crescimento radicular e a absorção de nutrientes pela soja, cv. E MBRAPA 58, e seus reflexos sobre a produção de grãos, considerando as doses de calcário e gesso na superfície, em sistema plantio direto, foi realizado um experimento em um Latossolo Vermelho distrófico textura média, em Ponta Grossa (PR). 0 delineamento experimental empregado foi o de blocos ao acaso em parcela subdividida, com três repetições. Foram utilizadas quatro doses de calcário dolomítico, com 84\% de PR NT: 0, 2, 4 e $6 \mathrm{t} \mathrm{ha}^{-1}$, e quatro doses de gesso agrícola: 0, 4, 8 e $12 \mathrm{t} \mathrm{ha}^{-1}$. A calagem foi realizada em julho e a aplicação de gesso em novembro de 1993 . 0 crescimento radicular da soja não foi afetado pelas condições de acidez, em solo com 15, 12 e $8 \mathrm{mmol}_{\mathrm{c}} \mathrm{dm}^{-3}$ de Ca trocável e 28, 32 e $40 \%$ de saturação por Al, respectivamente, nas profundidades de 0-10, 10-20 e $20-40 \mathrm{~cm}$. Houve aumento da absorção, pela cultura da soja, de todos os macronutrientes com a calagem, e de Ca e S com a aplicação de gesso. Somente a calagem aumentou a produção de soja, em decorrência de maior disponibilidade e absorção de $\mathrm{Mg}$ e de redução dos teores foliares de $\mathrm{Zn}$ e Mn.
\end{abstract}

Termos de indexação: Glycinemax (L.) Merrill, acidez, subsolo, nutrição mineral, sistema radicular.

\footnotetext{
(1) Recebido para publicação em maio de 2000 e aprovado em maio de 2001.

(2) Professor do Departamento de Ciência do Solo e Engenharia Agrícola da Universidade Estadual de Ponta Grossa - UEPG. Caixa Postal 992/3, CEP 84010-790 Ponta Grossa (PR). Bolsista do CNPq. E-mail: efcaires@uepg.br

(3) Mestrando em Solos e Nutrição de Plantas, Escola Superior de Agricultura Luiz de Queiroz - ESALQ/USP. Ex-bolsista do PIBICCNPq/UEPG. E-mail: affonsec@carpa.ciagri.usp.br

(4) Bolsista do PIBIC-CNPq/UEPG.
} 


\title{
SUMMARY: ROOT GROWTH AND NUTRIENT UPTAKE BY SOYBEAN AS AFFECTED BY LIME AND GYPSUM, UNDER A NO-TILLAGE SYSTEM
}

\begin{abstract}
Calcium deficiency and aluminum toxicity are considered to be the most important acidity factors limiting root growth. A field experiment was carried out on a dystrophic Red Latosol (Haplortox) in Ponta Grossa, Paraná, Brazil, to study the effects of surface application of lime and gypsum on root growth and nutrient uptake by soybean, CV. EMBRAPA 58, under no-tillage system. A randomized complete block design was used, with three replications, in a split-plot experiment. Dolomitic limestone was applied at rates of 0, 2, 4 and $6 \mathrm{t} \mathrm{ha}^{-1}$ (main plots) in J uly 1993; gypsum was applied at rates of 0, 4, 8 and $12 \mathrm{t} \mathrm{ha}^{-1}$ (subplots) in November 1993. The growth of soybean roots was not affected by acidity conditions in soil with 15,12 and $8 \mathrm{mmol}_{\mathrm{C}} \mathrm{dm}^{-3}$ of exchangeable $\mathrm{Ca}$ and 28,32 and $40 \%$ of $\mathrm{Al}$ saturation, respectively, in the $0-10,10-20$ and $20-40 \mathrm{~cm}$ layers. Liming improved soybean nutriti on and gypsum increased $\mathrm{Ca}$ and $\mathrm{S}$ uptake. Only limeapplication increased soybean yied, due to the larger availability and uptake of $\mathrm{Mg}$ and reduction of $\mathrm{Zn}$ and $\mathrm{Mn}$ contents in the leaves.
\end{abstract}

Index terms: Glycine max (L.) Merrill, acidity, subsoil, mineral nutrition, root system.

\section{NTRODUÇÃO}

A correção da acidez do solo é necessária para o aumento da produção agrícola, em decorrência da toxidez causada por Al e Mn e baixa saturação por bases, principalmenteCa (Coleman \& Thomas, 1967). A toxidez deAl (Pavan et al., 1982) ea deficiência de $\mathrm{Ca}$ (Ritchey et al., 1982) têm si do os fatores de acidez mais importantes na restrição do crescimento radicular.

O Al em concentrações tóxicas causa redução na taxa de crescimento de raízes (Horst et al., 1991), que se tornam mais lentas em al ongar, interferindo na absorção de nutrientes pelas plantas (Clarkson, 1967; McCormick \& Borden, 1972). A presença de Ca nas sol uções em contato com as raízes é essencial para sua sobrevivência, pois esse nutriente não se transloca da parte aérea para as porções novas das raízes em crescimento.

A calagem éa prática mais eficiente para el evar o pH, teores de Ca e saturação por bases e diminuir Al e Mn trocáveis no solo. São vários os trabalhos que demonstram aumentos consideráveis na produção de soja com a aplicação de calcário incorporado ao solo em sistema de cultivo convencional (Mascarenhas et al., 1969; Raij et al., 1977; Quaggio et al., 1982, 1993). Entretanto, trabalhos recentes têm mostrado altas produtividades da soja em solos ácidos sob plantio direto, com respostas pouco expressivas (Pöttker \& Ben, 1998) ou ausência de resposta (Caires et al., 1998, 1999) da cultura à aplicação de calcário na superfície.

A menor resposta da soja à calagem no sistema plantio direto tem sido relacionada com o menor efeito tóxico do Al, decorrente da formação de compl exos orgâni cos solúveis presentes nos resíduos vegetais (Miyazawa et al., 1996), ou com a disponibilidade suficiente de Ca e Mg trocáveis, mesmo em condições de alta acidez (Caires et al., 1998). Todavia, faltam informações a respeito das conseqüências das alterações químicas do solo, pela calagem na superfície, sobre o crescimento radicular e nutrição mineral da soja nesse sistema de cultivo.

As limitações à produtividade agrícola causadas pela acidez do subsolo, decorrentes da restrição ao crescimento radicular e da absorção de água e nutrientes pelas culturas, têm sido amplamente divulgadas na literatura (Pavan et al., 1982; Ritchey et al., 1982; Sumner et al., 1986; Farina \& Channon, 1988).

O gesso agrícola tem sido utilizado com a finalidade de aumentar osuprimento de Ca e reduzir a toxidez deAI no subsolo (Sumner, 1995), o que tem resultado em melhor crescimento de raízes em profundidade (Noble \& Sumner, 1988; Noble et al., 1988). Entretanto, as implicações do subsolo ácido sobre o crescimento radicular da soja cultivada no sistema plantio direto têm sido pouco estudadas.

O presente trabal ho foi realizado com o objetivo de avaliar o crescimento radicular e a absorção de nutrientes pela soja cultivada no sistema plantio direto, considerando as alterações químicas do solo pela aplicação de doses de calcário e gesso na superfície, bem como seus reflexos sobre a produção degrãos.

\section{MATERIAL E MÉTODOS}

O experimento foi realizado no município de Ponta Grossa (PR), Fazenda Estância dos Pinheiros, 
em um Latossolo Vermel ho distrófico, há 15 anos sob plantio direto. Análises químicas (Pavan et al., 1992) e granulométricas (EMBRAPA, 1997) do solo, da camada de $0-20 \mathrm{~cm}$, realizadas antes da instalação do experimento, revelaram os seguintes resultados: $\mathrm{pH}\left(\mathrm{CaCl}_{2}\right.$ 0,01 $\left.\mathrm{mol} \mathrm{L}^{-1}\right)$ 4,5; $58 \mathrm{mmol}_{\mathrm{c}} \mathrm{dm}^{-3} \mathrm{de}$ $\mathrm{H}^{+}+\mathrm{Al}^{3+} ; 6 \mathrm{mmol}_{\mathrm{C}} \mathrm{dm}^{-3} \mathrm{de} \mathrm{Al}^{3+} ; 16 \mathrm{mmol}_{\mathrm{C}} \mathrm{dm}^{-3} \mathrm{de}$ $\mathrm{Ca}^{2+} ; 10 \mathrm{mmol}_{\mathrm{C}} \mathrm{dm}^{-3} \mathrm{de} \mathrm{Mg}^{2+} ; 1,4 \mathrm{mmol}_{\mathrm{c}} \mathrm{dm}^{-3} \mathrm{de} \mathrm{K}^{+}$; $9 \mathrm{mg} \mathrm{dm}^{-3}$ deP (Mehlich-1); $19 \mathrm{~g} \mathrm{dm}^{-3}$ de C-orgânico e $32 \%$ de saturação por bases e teores de argila, silte e areia, respectivamente, de 220, 195 e $585 \mathrm{~g} \mathrm{~kg}^{-1}$.

O delineamento experimental empregado foi 0 de blocos completos ao acaso em parcelas subdivididas, com três repetições. Os tratamentos foram constituídos por quatro doses de calcário dolomítico, com $84 \%$ de poder relativo de neutralizaçãototal (PRNT): 0, 2, 4 e 6 t ha $^{-1}$, visando el evar a saturação por bases (V\%) da camada de 0$20 \mathrm{~cm}$ de sol o a 50, 70 e $90 \%$, e quatro doses de gesso agrícola: 0, 4, 8 e 12 t ha-1, equivalentes em cálcio às doses de cal cário. O cal cário foi aplicado, nas parcelas principais, em julho, e o gesso, nas subparcelas, em novembro de 1993, sendo ambas as aplicações feitas a Ianço na superfície do solo.

As parcelas, com 6,3 m de largura e $32,0 \mathrm{~m}$ de comprimento, foram divididas em quatrosubparcelas de 8,0 m de comprimento. Na rotação de culturas, foram utilizados: soja (1993/94), aveia preta/ ervilhaca (inverno/94), milho (1994/95), pousio (inverno/95), soja (1995/96), trigo (inverno/96), soja (1996/97), triticale (inverno/97), soja (1997/98), aveia preta (inverno/98) e soja (1998/99). O crescimento radicular e a absorção de nutrientes pela soja, deste trabal ho, foram avaliados nesteúltimo ano agrícola.

A semeadura da soja, cultivar EMBRAPA 58, foi feita em 30 de outubro de 1998, na densidade de 20 sementes por metrolinear e espaçamento de 0,45 m entre as linhas. A adubação básica utilizada na semeadura foi de $250 \mathrm{~kg} \mathrm{ha}^{-1}$ da fórmula 0-26-26. Realizou-se, também, a inoculação das sementes com estirpes sel ecionadas de Bradyrhizobium japonicum. A temperatura média do ar e a precipitação pluvial durante o ciclo da cultura foram, respectivamente, de $22^{\circ} \mathrm{C}$ e $764 \mathrm{~mm}$. A precipitação pluvial foi bem distribuída, tendo ocorrido uma estiagem somente no mês de novembro, logo após a emergência das plântulas, o quenão comprometeu o desenvolvimento da cultura.

No início do florescimento da cultura, foi feita amostragem de fol has, col etando-se a terceira fol ha a partir do ápice das plantas, em número de 30 por subparcela, para análise química dos teores de N, P, $\mathrm{K}, \mathrm{Ca}, \mathrm{Mg}, \mathrm{S}, \mathrm{Zn}$ e $\mathrm{Mn}$, de acordo com os métodos descritos por Malavolta et al. (1997).

No estádio $R_{6}$ da escala de Fehr et al. (1971), foram retirados 2,0 m de linha contínua de plantas de cada subparcela, somente a parte aérea, para avaliar a absorção de nutrientes. Essas amostras foram separadas em fol has, hastes e vagens, determinando-se a produção de matéria seca e os teores de N, P, K, Ca, Mg e S, nas diferentes partes da planta, segundo Malavolta et al. (1997). Nessa época, também col etaram-se amostras de raízes, por meio de trado cilíndrico em quatro profundidades (0-10, 10-20, 20-40 e 40-60 cm), retirando-se 10 subamostras, sendo cinco na linha de semeadura e cinco nas entrelinhas, para compor uma amostra composta. As amostras, com 3,5 cm de diâmetro, foram tomadas ao acaso, apenas em quatro tratamentos de calcário (C) egesso (G): Testemunha $\left(\mathrm{C}_{0} \mathrm{G}_{0}\right)$, Calcário $\left(\mathrm{C}_{4} \mathrm{G}_{0}\right)$, Gesso $\left(\mathrm{C}_{0} \mathrm{G}_{8}\right)$ e Calcário + Gesso $\left(C_{4} G_{8}\right)$. As raízes foram separadas do sol o por dispersão em água, utilizando peneira de $0,5 \mathrm{~mm}$. $O$ comprimento de raízes foi estimado pel o método de Tennant (1975) eo raio médioe a superfície radicular segundo Hallmark \& Barber (1984).

Após a maturação, a soja foi colhida e trilhada, sendo então determinada a produção de grãos a 13\% de umidade. Foram col hidas as seis linhas centrais por quatro metros de comprimento em cada subparcela, tendo sido desprezados dois metros de cada extremidade.

Após a col heita, foram col etadas amostras de solo, retirando-se 12 subamostras por subparcela, para compor uma amostra composta das camadas de 0-5, 5-10 e 10-20 cm, e cinco subamostras, para as camadas de 20-40 e 40-60 cm de profundidade, para análise acompanhamento do efeito dos tratamentos na acidez e nos teores de nutrientes do solo, deacordo com os métodos descritos por Pavan et al. (1992).

A resistência do solo à penetração foi avaliada por meio de penetrômetro de impacto, após a col heita, em 10 pontos ao acaso dentro da área experimental, atéà profundidade de $60 \mathrm{~cm}$, conforme o método de Stolf (1991).

Os resultados foram submetidos às análises de variância e de regressão. Na ausência de significância da interação cal cário x gesso sobre as variáveis estudadas, as equações foram ajustadas pelas médias das observações, adotando-se como critério para escolha do modelo a magnitude dos coeficientes de determinação significativos a $5 \%$. A análise de variância, para os resultados de raízes (densidade, superfície radicular e raio médio), foi efetuada para cada profundidade de amostragem, comparando-se as médias pel o teste deTukey a 5\% de probabilidade.

\section{RESULTADOS E DISCUSSÃO}

A calagem proporcionou aumentos significativos no pH, Ca e Mg trocáveis e saturação por bases e redução significativa nos teores de Al trocável e $\mathrm{H}+\mathrm{Al}$, nas cinco profundidades estudadas (Quadro 1). Os aumentos do pH, Ca e Mg trocáveis e saturação por bases e a redução dos teores de Al 
trocável e H +Al nas camadas de 20-40 e 40-60 cm mostram claramente os efeitos positivos do cal cário aplicado na superfície sobre a correção da acidez do subsolo. Ressalta-se que essa avaliação foi realizada 68 meses após a aplicação do cal cário.

A aplicação de doses de gesso (Quadro 2) aumentou significativamente os teores de $\mathrm{Ca}$ trocável no perfil do solo e causou redução significativa nos teores de Al e de Mg trocáveis (510 e 10-20 cm). O gesso também aumentou os teores deS-SO ${ }_{4}^{2-}$ do solo, princi pal mentenas camadas mais profundas. Na maior dose de gesso $\left(12 \mathrm{t} \mathrm{ha}^{-1}\right)$, o teor de $\mathrm{S}_{-} \mathrm{SO}_{4}{ }^{2-}$ aumentou de 9 para $14 \mathrm{mg} \mathrm{dm}^{-3}, 12$ para $15 \mathrm{mg} \mathrm{dm}^{-3}, 13$ para $25 \mathrm{mg} \mathrm{dm}^{-3}, 23$ para $40 \mathrm{mg} \mathrm{dm}^{-3}$ e de 32 para $60 \mathrm{mg} \mathrm{dm}^{-3}$, respectivamente, nas profundidades de 0-5, 5-10, 10-20, 20-40 e 40-60 cm. Considerando o tempo de aplicação do gesso
(64 meses), o seu efeito noaumento do $\mathrm{Ca}$ e doS-SO ${ }_{4}{ }^{2-}$ do solo foi duradouro, apesar da intensa lixiviação ocorrida. Na dosemáxima degesso (12 t ha-1), quando foram aplicados cerca de $60 \mathrm{mmol}_{\mathrm{c}} \mathrm{dm}^{-3}$ de Ca e $960 \mathrm{mg} \mathrm{dm}^{-3} \mathrm{deS} \mathrm{SO}_{4}{ }^{2-}$, foi possível recuperar, aproximadamente, $12 \mathrm{mmol}_{\mathrm{c}} \mathrm{dm}^{-3}$ de Ca e $54 \mathrm{mg} \mathrm{dm}^{-3}$ de S-SO ${ }_{4}^{2-}$, atéa profundidade de $60 \mathrm{~cm}$. I sso significa que, após 64 meses, cerca de $80 \%$ do Ca e $95 \%$ do $\mathrm{S}-\mathrm{SO}_{4}{ }^{2-}$ da dose máxima de gesso aplicada ( $12 \mathrm{t} \mathrm{ha}^{-1}$ ) foram absorvidos pelas plantas e, ou, lixiviados para profundidades superiores a $60 \mathrm{~cm}$.

A figura 1 compara os efeitos de quatro tratamentos de calcário e gesso no crescimento do sistema radicular da soja e em atributos da fertilidade do solo. Os tratamentos não influenciaram significativamente a densidade de comprimento, a superfície radicular e oraio médio das raízes de soja,

Quadro 1. Variações nas características químicas, para diferentes profundidades do solo, considerando doses de calcário na superfície, após 68 meses, em sistema plantio direto

\begin{tabular}{|c|c|c|c|c|c|c|c|c|c|}
\hline \multirow{2}{*}{ Profundidade } & \multirow{2}{*}{ Calcário } & \multirow{2}{*}{ pH em $\mathrm{CaCl}_{2}$} & \multirow{2}{*}{$\mathrm{H}^{+}+\mathrm{Al}^{3+}$} & \multicolumn{4}{|c|}{ Cátion trocável } & \multirow{2}{*}{ P (Mehlich-1) } & \multirow{2}{*}{$\begin{array}{l}\text { Saturação } \\
\text { por bases }\end{array}$} \\
\hline & & & & $\mathbf{A l}^{3+}$ & $\mathrm{Ca}^{2+}$ & $\mathbf{M g}^{2+}$ & $\mathbf{K}^{+}$ & & \\
\hline $\mathrm{cm}$ & \multicolumn{2}{|l|}{ t ha-1 } & \multicolumn{5}{|c|}{$-\mathrm{mmol}_{\mathrm{c}} \mathrm{dm}^{-3}$} & $\mathrm{mg} \mathrm{dm}^{-3}$ & $\%$ \\
\hline \multirow[t]{3}{*}{$0-5$} & $\begin{array}{l}0 \\
2 \\
4 \\
6\end{array}$ & $\begin{array}{l}4,0 \\
4,6 \\
5,1 \\
5,5\end{array}$ & $\begin{array}{r}104 \\
82 \\
57 \\
46\end{array}$ & $\begin{array}{l}9 \\
2 \\
0 \\
0\end{array}$ & $\begin{array}{l}20 \\
39 \\
46 \\
49\end{array}$ & $\begin{array}{l}10 \\
12 \\
20 \\
25\end{array}$ & $\begin{array}{l}3,6 \\
4,0 \\
3,8 \\
3,8\end{array}$ & $\begin{array}{l}14 \\
14 \\
14 \\
14\end{array}$ & $\begin{array}{l}24 \\
40 \\
55 \\
63\end{array}$ \\
\hline & Efeito & $\mathrm{L}^{* *(1)}$ & $\mathrm{L}^{* *}$ & $\mathrm{~L}^{* *}$ & $\mathrm{~L}^{* *}$ & $\mathrm{~L}^{* *}$ & ns & ns & $\mathrm{L} * *$ \\
\hline & C.V. (\%) & 2,0 & 6,8 & 37,9 & 11,8 & 15,4 & 12,9 & 21,3 & 11,7 \\
\hline \multirow[t]{3}{*}{$5-10$} & $\begin{array}{l}0 \\
2 \\
4 \\
6\end{array}$ & $\begin{array}{l}4,0 \\
4,2 \\
4,5 \\
4,6\end{array}$ & $\begin{array}{r}102 \\
95 \\
76 \\
71\end{array}$ & $\begin{array}{l}9 \\
6 \\
3 \\
3\end{array}$ & $\begin{array}{l}17 \\
22 \\
29 \\
32\end{array}$ & $\begin{array}{r}9 \\
11 \\
13 \\
15\end{array}$ & $\begin{array}{l}1,6 \\
1,5 \\
1,5 \\
1,3\end{array}$ & $\begin{array}{r}10 \\
8 \\
9 \\
8\end{array}$ & $\begin{array}{l}21 \\
27 \\
36 \\
40\end{array}$ \\
\hline & Efeito & $\mathrm{L}^{* *}$ & $\mathrm{~L}^{* *}$ & $L^{* *}$ & $\mathrm{~L}^{* *}$ & $\mathrm{~L}^{* *}$ & $L^{*}$ & ns & $\mathrm{L}^{* *}$ \\
\hline & C.V. (\%) & 3,1 & 7,4 & 23,2 & 12,7 & 25,0 & 19,0 & 34,1 & 16,0 \\
\hline \multirow[t]{3}{*}{$10-20$} & $\begin{array}{l}0 \\
2 \\
4 \\
6\end{array}$ & $\begin{array}{l}4,0 \\
4,1 \\
4,3 \\
4,4\end{array}$ & $\begin{array}{l}94 \\
92 \\
79 \\
78\end{array}$ & $\begin{array}{l}9 \\
7 \\
5 \\
5\end{array}$ & $\begin{array}{l}14 \\
16 \\
19 \\
20\end{array}$ & $\begin{array}{r}8 \\
9 \\
10 \\
10\end{array}$ & $\begin{array}{l}1,3 \\
1,2 \\
1,0 \\
1,0\end{array}$ & $\begin{array}{l}3 \\
3 \\
3 \\
3\end{array}$ & $\begin{array}{l}20 \\
22 \\
27 \\
28\end{array}$ \\
\hline & Efeito & L** & $\mathrm{L}^{* *}$ & $L^{* *}$ & $\mathrm{~L}^{* *}$ & $\mathrm{~L}^{* *}$ & $\mathrm{~L}^{* *}$ & ns & $\mathrm{L}^{* *}$ \\
\hline & C.V. (\%) & 2,2 & 4,6 & 13,8 & 14,9 & 13,3 & 17,8 & 29,2 & 12,6 \\
\hline \multirow[t]{3}{*}{$20-40$} & $\begin{array}{l}0 \\
2 \\
4 \\
6\end{array}$ & $\begin{array}{l}4,0 \\
4,1 \\
4,3 \\
4,3\end{array}$ & $\begin{array}{l}85 \\
84 \\
77 \\
74\end{array}$ & $\begin{array}{l}9 \\
8 \\
6 \\
5\end{array}$ & $\begin{array}{l}11 \\
13 \\
16 \\
18\end{array}$ & $\begin{array}{r}8 \\
9 \\
10 \\
11\end{array}$ & $\begin{array}{l}1,1 \\
1,1 \\
1,0 \\
0,9\end{array}$ & $\begin{array}{l}2 \\
2 \\
2 \\
3\end{array}$ & $\begin{array}{l}19 \\
22 \\
26 \\
29\end{array}$ \\
\hline & Efeito & $L^{* *}$ & $\mathrm{~L}^{* *}$ & $L^{* *}$ & $\mathrm{~L}^{* *}$ & $\mathrm{~L}^{* *}$ & $\mathrm{~L}^{* *}$ & ns & $\mathrm{L} * *$ \\
\hline & C.V. (\%) & 3,2 & 9,3 & 23,5 & 19,8 & 14,9 & 19,5 & 35,6 & 15,9 \\
\hline \multirow[t]{3}{*}{$40-60$} & $\begin{array}{l}0 \\
2 \\
4 \\
6\end{array}$ & $\begin{array}{l}4,1 \\
4,2 \\
4,3 \\
4,3\end{array}$ & $\begin{array}{l}75 \\
75 \\
74 \\
71\end{array}$ & $\begin{array}{l}7 \\
6 \\
5 \\
4\end{array}$ & $\begin{array}{l}11 \\
13 \\
14 \\
15\end{array}$ & $\begin{array}{r}9 \\
10 \\
10 \\
12\end{array}$ & $\begin{array}{l}0,8 \\
0,9 \\
0,7 \\
0,7\end{array}$ & $\begin{array}{l}- \\
- \\
- \\
-\end{array}$ & $\begin{array}{l}22 \\
24 \\
25 \\
28\end{array}$ \\
\hline & Efeito & $L^{* *}$ & $\mathrm{~L}^{* *}$ & $\mathrm{~L}^{* *}$ & $\mathrm{~L} * *$ & $\mathrm{~L}^{* *}$ & $\mathrm{~L} * *$ & - & $\mathrm{L} * *$ \\
\hline & C.V. (\%) & 2,8 & 5,9 & 21,6 & 13,7 & 14,9 & 19,6 & - & 13,5 \\
\hline
\end{tabular}

(1) $\mathrm{L}=$ Efeito linear por regressão polinomial. *, ** e ns: Significativos a 5 e $1 \%$ e não-significativo. 
Quadro 2. Variações nas características químicas, para diferentes profundidades do solo, considerando doses de gesso na superfície, após 64 meses, em sistema plantio direto

\begin{tabular}{|c|c|c|c|c|c|c|c|c|c|}
\hline \multirow{2}{*}{ Profundidade } & \multirow{2}{*}{ Gesso } & \multirow{2}{*}{ pH em $\mathrm{CaCl}_{2}$} & \multirow{2}{*}{$\mathrm{H}^{+}+\mathrm{Al}^{3+}$} & \multicolumn{4}{|c|}{ Cátion trocável } & \multirow{2}{*}{ P (Mehlich-1) } & \multirow{2}{*}{$\begin{array}{l}\text { Saturação } \\
\text { por bases }\end{array}$} \\
\hline & & & & $\mathrm{Al}^{3+}$ & $\mathrm{Ca}^{2+}$ & $\mathbf{M g}^{2+}$ & $\mathbf{K}^{+}$ & & \\
\hline $\mathrm{cm}$ & t ha-1 & & 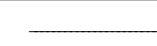 & $-\mathrm{mm}$ & $\mathrm{ol}_{\mathrm{c}} \mathrm{dm}^{-3}$ & 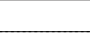 & - & $\mathrm{mg} \mathrm{dm}^{-3}$ & $\%$ \\
\hline \multirow[t]{3}{*}{$0-5$} & $\begin{array}{r}0 \\
4 \\
8 \\
12\end{array}$ & $\begin{array}{l}4,7 \\
4,7 \\
4,8 \\
4,7\end{array}$ & $\begin{array}{l}72 \\
73 \\
69 \\
75\end{array}$ & $\begin{array}{l}3 \\
3 \\
3 \\
3\end{array}$ & $\begin{array}{l}34 \\
37 \\
40 \\
42\end{array}$ & $\begin{array}{l}17 \\
17 \\
16 \\
17\end{array}$ & $\begin{array}{l}3,7 \\
4,1 \\
3,6 \\
4,0\end{array}$ & $\begin{array}{l}14 \\
14 \\
14 \\
14\end{array}$ & $\begin{array}{l}43 \\
44 \\
46 \\
46\end{array}$ \\
\hline & Efeito & ns & ns & ns & $\mathrm{L}^{* *(1)}$ & ns & ns & ns & ns \\
\hline & C.V. (\%) & 2,0 & 6,5 & 33,0 & 8,2 & 10,7 & 12,2 & 18,5 & 9,4 \\
\hline \multirow[t]{3}{*}{$5-10$} & $\begin{array}{r}0 \\
4 \\
8 \\
12\end{array}$ & $\begin{array}{l}4,3 \\
4,3 \\
4,3 \\
4,4\end{array}$ & $\begin{array}{l}88 \\
87 \\
84 \\
84\end{array}$ & $\begin{array}{l}6 \\
6 \\
5 \\
5\end{array}$ & $\begin{array}{l}23 \\
24 \\
26 \\
27\end{array}$ & $\begin{array}{l}13 \\
12 \\
12 \\
11\end{array}$ & $\begin{array}{l}1,4 \\
1,5 \\
1,5 \\
1,4\end{array}$ & $\begin{array}{r}10 \\
8 \\
8 \\
10\end{array}$ & $\begin{array}{l}30 \\
30 \\
32 \\
32\end{array}$ \\
\hline & Efeito & ns & ns & $\mathrm{L}^{*}$ & L** & $\mathrm{L}^{*}$ & ns & ns & ns \\
\hline & C.V. (\%) & 2,7 & 7,5 & 19,3 & 11,0 & 17,4 & 14,9 & 34,5 & 12,7 \\
\hline \multirow[t]{3}{*}{$10-20$} & $\begin{array}{r}0 \\
4 \\
8 \\
12\end{array}$ & $\begin{array}{l}4,2 \\
4,2 \\
4,2 \\
4,2\end{array}$ & $\begin{array}{l}86 \\
88 \\
85 \\
84\end{array}$ & $\begin{array}{l}7 \\
7 \\
6 \\
6\end{array}$ & $\begin{array}{l}15 \\
16 \\
18 \\
19\end{array}$ & $\begin{array}{r}10 \\
10 \\
9 \\
9\end{array}$ & $\begin{array}{l}1,1 \\
1,2 \\
1,1 \\
1,1\end{array}$ & $\begin{array}{l}3 \\
3 \\
3 \\
3\end{array}$ & $\begin{array}{l}23 \\
24 \\
25 \\
26\end{array}$ \\
\hline & Efeito & ns & ns & $\mathrm{L}^{*}$ & $L^{* *}$ & $\mathrm{~L}^{*}$ & ns & ns & ns \\
\hline & C.V. (\%) & 1,6 & 4,5 & 9,4 & 12,3 & 11,3 & 16,6 & 25,6 & 11,2 \\
\hline \multirow[t]{3}{*}{$20-40$} & $\begin{array}{r}0 \\
4 \\
8 \\
12\end{array}$ & $\begin{array}{l}4,2 \\
4,1 \\
4,2 \\
4,2\end{array}$ & $\begin{array}{l}80 \\
81 \\
79 \\
80\end{array}$ & $\begin{array}{l}7 \\
8 \\
7 \\
6\end{array}$ & $\begin{array}{l}13 \\
13 \\
15 \\
17\end{array}$ & $\begin{array}{r}9 \\
10 \\
10 \\
9\end{array}$ & $\begin{array}{l}1,0 \\
1,1 \\
1,0 \\
1,0\end{array}$ & $\begin{array}{l}2 \\
2 \\
2 \\
3\end{array}$ & $\begin{array}{l}22 \\
23 \\
25 \\
25\end{array}$ \\
\hline & E feito & ns & ns & ns & $L^{* *}$ & ns & ns & ns & ns \\
\hline & C.V. (\%) & 2,9 & 10,2 & 21,5 & 13,9 & 14,0 & 21,4 & 34,8 & 14,9 \\
\hline \multirow[t]{3}{*}{$40-60$} & $\begin{array}{r}0 \\
4 \\
8 \\
12\end{array}$ & $\begin{array}{l}4,2 \\
4,2 \\
4,2 \\
4,3\end{array}$ & $\begin{array}{l}74 \\
74 \\
74 \\
73\end{array}$ & $\begin{array}{l}6 \\
6 \\
6 \\
6\end{array}$ & $\begin{array}{l}12 \\
13 \\
14 \\
15\end{array}$ & $\begin{array}{l}11 \\
10 \\
10 \\
10\end{array}$ & $\begin{array}{l}0,7 \\
0,8 \\
0,8 \\
0,8\end{array}$ & $\begin{array}{l}- \\
- \\
- \\
-\end{array}$ & $\begin{array}{l}24 \\
24 \\
25 \\
26\end{array}$ \\
\hline & E feito & ns & ns & ns & $\mathrm{L}^{* *}$ & ns & ns & - & ns \\
\hline & C.V. (\%) & 1,4 & 5,3 & 11,0 & 8,3 & 14,7 & 18,1 & - & 11,6 \\
\hline
\end{tabular}

(1) $\mathrm{L}=$ Efeito linear por regressão polinomial. *, ** e ns: Significativos a 5 e 1\% e não-significativo.

nas quatro profundidades estudadas. O crescimento radicular foi semel hante, apesar das alterações nas características químicas das camadas superficiais e do subsolo, com a aplicação de cal cário e, ou, gesso. Nota-se que, na camada superficial do solo $(0-10 \mathrm{~cm})$, o teor de Ca variou de 15 a $40 \mathrm{mmol}_{\mathrm{c}} \mathrm{dm}^{-3}$, o teor de Al trocável de 0 a $11 \mathrm{mmol}_{\mathrm{c}} \mathrm{dm}^{-3}$ e a saturação por Al de 0 a 28\%, sem causar al terações no crescimento radicular. O aumento do Ca trocável de 8 para $18 \mathrm{mmol}_{\mathrm{C}} \mathrm{dm}^{-3}$ e a redução do Al trocável de 11 para $5 \mathrm{mmol}_{\mathrm{c}} \mathrm{dm}^{-3}$ e da saturação por Al de 40 para $15 \%$, em profundidade $(20-40 \mathrm{~cm})$ também não proporcionaram maior enraizamento da planta.
O Ca tem papel preponderante no crescimento radicular, mas os limites críticos do nutriente para o crescimento de raízes parecem ser muito baixos. Ritchey et al. (1982) mostraram que 1,0 a $1,5 \mathrm{mmol}_{\mathrm{c}} \mathrm{dm}^{-3}$ de Ca normalizavam o crescimento deraízes de plântulas. Crescimento normal deraízes de soja também foi observado em solo com teor de Ca de 8,5 $\mathrm{mmol}_{\mathrm{c}} \mathrm{dm}^{-3}$ (Rosolem \& Marcello, 1998). Isso explica a ausência de resposta do sistema radicular observada ao aumento de Ca no solo. Mesmo assim, trabalhos têm demonstrado quea soja respondeem crescimento de raízes a teores bem mais elevados de $\mathrm{Ca}$, da ordem de $15 \mathrm{mmol}_{\mathrm{c}} \mathrm{dm}^{-3}$ (Rosolem 
(a)

DENSIDADE DE RAÍZES, $\mathrm{cm} \mathrm{cm}^{-3}$ SUPERFÍCIE RADICULAR, $\mathrm{cm}^{2} \mathrm{~cm}^{-3}$ RAIO MÉDIO DE RAÍZES, mm

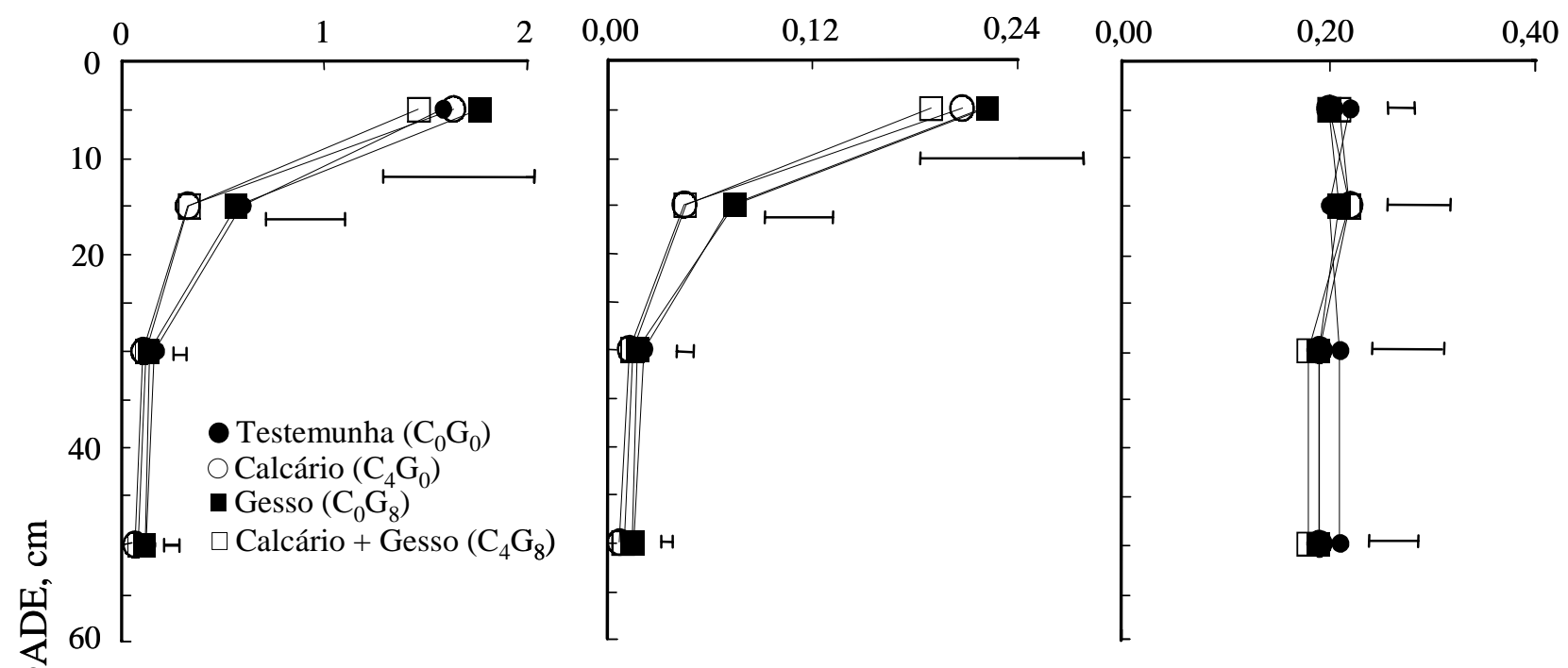

(b)
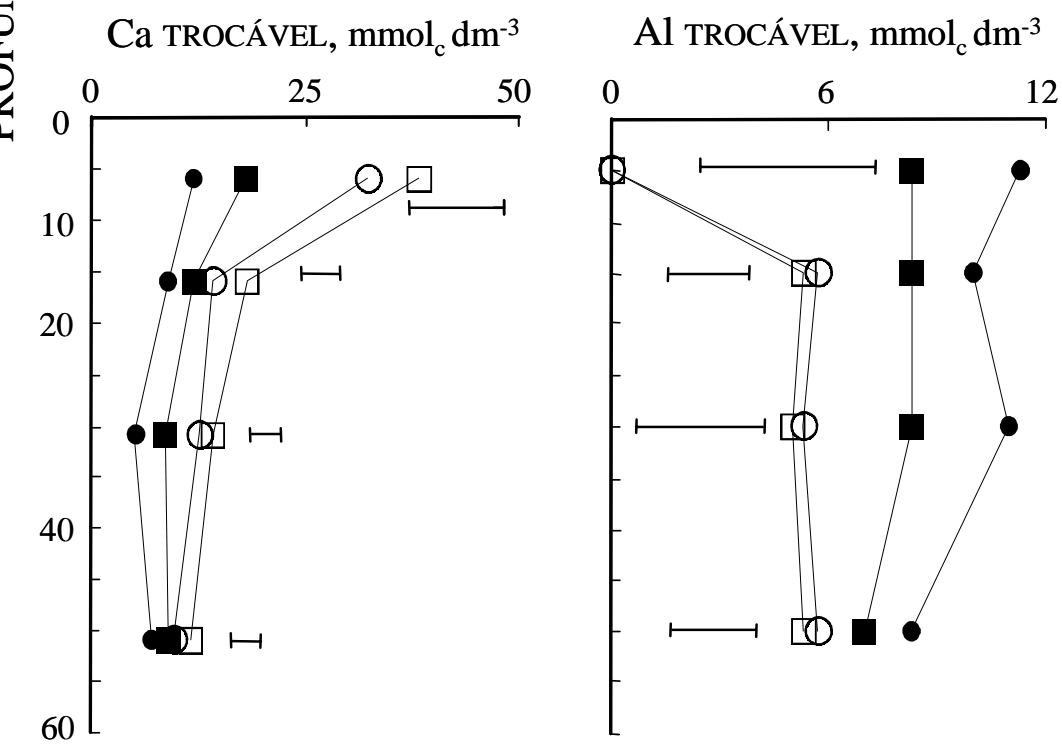

SATURAÇÃO POR ALUMÍNIO, \%

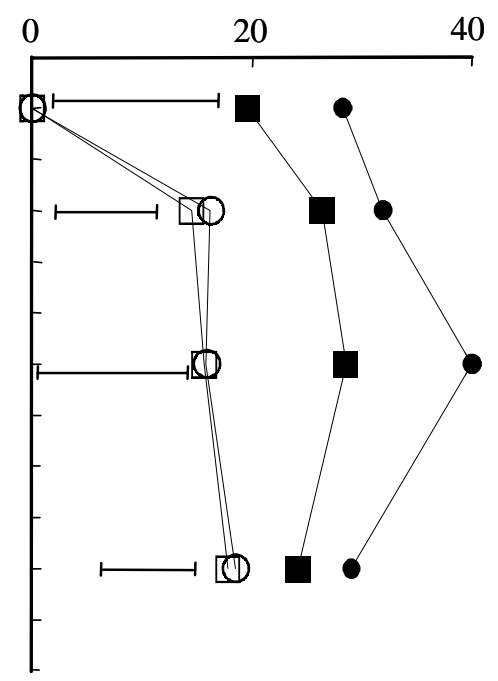

Figura 1. E feito da calagem e aplicação de gesso nas características de crescimento de raízes de soja (a) e em atri butos da fertilidade do solo (b), considerando a profundidade. Barras horizontais indicam o DMS pelo teste de Tukey a $5 \%$.

et al., 1995), da mesma forma que o amendoim (Caires \& Rosolem, 1991) e o milho (Rosolem et al., 1994). Cabe ressaltar que existem diferenças entre espécies evariedades de plantas, ocorrendo controle genético da eficiência das plantas na utilização de Ca (Clark, 1976 citado por Raij, 1988).

O Al em concentrações tóxicas causa redução na taxa de crescimento de raízes, mas a reação dos genótipos ao Al existente em sol os ácidos é variável. O genótipo utilizado no presente estudo foi desenvolvido em programa de melhoramento, visando aumentar a produtividade. É de ciclo de maturação precoce e ainda não existem trabalhos que o caracterizem quanto à sua tolerância ao Al. Mesmo assim, esperava-se obter maior resposta do sistema radicular à redução doAl trocável, pois esse genótipo é recomendado para solos de alta fertilidade. Deve-se considerar que a toxidez de Al no plantio direto é menor em relação ao sistema convencional de preparo do solo (Salet et al., 1996). 
Esse menor efeito tóxico do Al, em sistemas em que resíduos vegetais são mantidos na superfície do solo (plantio direto), édecorrente da formaçãodecomplexos orgânicos solúveis presentes nos restos das plantas (Miyazawa et al., 1996; Franchini et al., 1999).

Apesar da importância da identificação da tolerância à toxidez do Al nos genótipos de soja, estudos têm mostrado que o aprofundamento do sistema radicular da soja, independentemente das diferenças genotípicas, não tem sido muito afetado pela alta saturação por Al no subsolo, na ausência de déficit hídrico. É o caso dos resultados obtidos por Silva et al. (1984), mediante avaliação de 10 genóti pos de soja, quatro del es caracterizados como sensíveis aoAl pel o trabalho de Menosso et al. (2000): UFV 1, Cristalina, Paraná e IAC 6. O estudo foi realizado em vasos constituídos pela sobreposição de quatro camadas de solo com níveis diferentes de calagem, formando um gradiente com $0,17,2,46,5$ e $73,5 \%$ de saturação por Al. Foi observado que os 10 genótipos testados apresentaram comportamento semelhante quanto à distribuição do sistema radicular, em todos os anéis dos vasos.

Resultados semel hantes foram obtidos por Sartain \& Kamprath (1975) que, testando 12 cultivares de soja, em amostras de solo com $81 \%$ de saturação por Al, verificaram que o comprimento de raízes não foi influenciado pela presença do Al. Entretanto, em diversos trabalhos, principalmente em solução nutritiva, a presença de AI tem causado diferenças marcantes no crescimento radicular da soja (Arminger et al., 1968; Foy et al., 1969; Sartain \& Kamprath, 1978; Hanson \& Kamprath, 1979).

A camada de solo onde houve maior densidade de raízes $(0-10 \mathrm{~cm})$ foi também a que apresentou maior resistência ao penetrômetro. Os valores médios de resistência à penetração obtidos foram de $4,1,2,7,1,8$ e 1,3 $\mathrm{Mpa}$, respectivamente, nas camadas de 0-10, 10-20, 20-40 e 40-60 cm. A maior compactação em superfície no sistema plantio direto é ocasionada pela ausência de preparo do solo, aliada ao tráfego de máquinas (Tormena et al., 1998). Dessa forma, não há evidências de que tenha ocorrido limitação física no subsolo para impor restrição ao crescimento radicular da soja.

Como o crescimento de raízes não foi alterado (Figura 1), independentemente dos teores de Ca e Al trocáveis e dos valores de saturação por Al das camadas superficiais e do subsolo, mesmo sem haver restrições físicas ao mai or crescimento radicular em profundidade, pode-se inferir que a distribuiç̧ão do sistema radicular da soja esteve relacionada com a própria natureza morfológica do genótipo utilizado. Deve-se considerar que não ocorreu déficit hídrico durante o ciclo da cultura. Não havendo limitação deágua e nutrientes, a planta concentra suas raízes nas camadas onde o crescimento é mais fácil, procurando não prejudicar o processo de absorção (Marschner, 1986). Os danos causados na soja, em decorrência de períodos de seca durante o seu ciclo, devem estar relacionados com aspectos nutricionais, pela importância da umidade nos processos de transporte e absorção de nutrientes.

A calagem aumentou os teores de $\mathrm{Ca}$ e $\mathrm{Mg}$ e reduziu as concentrações de $\mathrm{Zn}$ e $\mathrm{Mn}$ nas fol has de soja, enquanto as doses de gesso aumentaram somente os teores foliares de Ca (Quadro 3). Houve pequena redução na concentração de $\mathrm{N}$ nas folhas com a calagem, por efeito de diluição do nutriente nos tecidos da planta, considerando a mai or produção de matéria seca (Figura 2).

A produção de matéria seca da soja aumentou significativamente com a calagem, graças à maior produção de hastes e vagens (Figura 2). A aplicação de doses de gesso não influenciou a produção de matéria seca pelas diferentes partes da planta. A produção total de matéria seca, 108 dias após a semeadura (estádio $\mathrm{R}_{6}$ da escal a de Fehr et al., 1971), variou de 5.360 a $6.350 \mathrm{~kg} \mathrm{ha}^{-1}$, tendo ocorrido um aumento de $990 \mathrm{~kg} \mathrm{ha}^{-1}$ (18\%), com a aplicação da maior dose de calcário ( $\left.6 \mathrm{t} \mathrm{ha}^{-1}\right)$. Esses valores de matéria seca estão bem próximos dos obtidos por Bataglia \& Mascarenhas (1977). Embora existam variações dependendo do tipo de sol o, clima e cultivar, é nesse estádio que ocorre o maior acúmulo de matéria seca pela planta de soja (Cordeiro et al., 1979).

A calagem aumentou a absorção de todos os macronutrientes pela cultura da soja (Figura 3). O aumento na absorção de N, P, K eS foi devido à maior extração desses nutrientes pelas hastes e vagens. A maior absorção de $\mathrm{Ca}$ e de $\mathrm{Mg}$ foi ocasionada pela mai or extração desses nutrientes, respectivamente, pelas fol has, vagens e por toda a parte aérea. Cabe ressaltar que esse aumento da absorção de nutrientes não foi ocasionado por modificações no crescimento de raízes, mas, sim, pelas alterações na disponibilidade dos nutrientes no solo.

O aumento da absor ção de $\mathrm{N}$ demonstra os efeitos benéficos da calagem no processo de fixação simbiótica do $\mathrm{N}_{2}$, os quais estão associados com a mai or disponibilidade de Mo e redução da aci dez do sol o. A extração de N pela parte aérea correlacionouse positiva e significativamente com a el evação da relação Ca/M $n$ nas fol has $(r=0,60)$, concordando com os resultados obtidos por Quaggio et al. (1982). A importância dessa correl ação para legumi nosas está ligada aos efeitos tóxicos do Mn sobre o sistema de fixação simbiótica do $\mathrm{N}_{2}$.

Houve maior absorção de $\mathrm{P}$ e $\mathrm{K}$ com a calagem, apesar de a análise de solo não ter revelado maior disponibilidade de $\mathrm{P}$ e aparente redução de $\mathrm{K}$ trocável (Quadro 1). Em solos ácidos, a calagem aumenta a disponibilidadedeP adsorvido nos óxidos de $\mathrm{Fe}$ e Al, mas o extrator Mehlich-1 não tem detectado esse efeito do cal cário (Quaggio et al., 1982; Raij \& Quaggio, 1990). Mesmo que a redução do K trocável $(5-60 \mathrm{~cm})$ tenha sido pequena, esses 
Quadro 3. Teores de nutrientes nas folhas de soja, considerando a aplicação de doses de calcário e gesso na superfície em sistema plantio direto

\begin{tabular}{|c|c|c|c|c|c|c|c|c|}
\hline Tratamento & $\mathbf{N}$ & $\mathbf{P}$ & $\mathbf{K}$ & $\mathrm{Ca}$ & Mg & $\mathbf{S}$ & Zn & Mn \\
\hline & \multicolumn{6}{|c|}{$\mathrm{g} \mathrm{kg}^{-1}$} & \multicolumn{2}{|c|}{$\mathrm{mg} \mathrm{kg}^{-1}$} \\
\hline \multicolumn{9}{|c|}{ Calcário, t ha-1 } \\
\hline 0 & 55,7 & 4,8 & 23,2 & 9,8 & 2,4 & 3,0 & 54,3 & 127,3 \\
\hline 2 & 54,9 & 4,5 & 22,1 & 11,1 & 2,7 & 2,9 & 48,6 & 107,5 \\
\hline 4 & 54,0 & 4,4 & 22,3 & 11,3 & 3,0 & 3,0 & 39,4 & 85,8 \\
\hline 6 & 52,4 & 4,4 & 23,1 & 12,3 & 3,1 & 2,8 & 35,5 & 83,7 \\
\hline Efeito & $\mathrm{L}^{*(1)}$ & ns & ns & $L^{*}$ & $\mathrm{~L}^{* *}$ & ns & $\mathrm{L}^{* *}$ & $\mathrm{~L}^{* *}$ \\
\hline C.V. (\%) & 6,3 & 12,7 & 11,2 & 10,9 & 11,0 & 7,6 & 16,7 & 13,2 \\
\hline \multicolumn{9}{|c|}{ Gesso, t ha-1 } \\
\hline 0 & 54,7 & 4,5 & 21,7 & 10,2 & 2,9 & 2,9 & 45,7 & 100,8 \\
\hline 4 & 54,7 & 4,6 & 23,2 & 10,8 & 2,8 & 2,9 & 41,8 & 96,8 \\
\hline 8 & 52,8 & 4,5 & 22,8 & 11,7 & 2,8 & 2,9 & 43,3 & 102,2 \\
\hline 12 & 54,8 & 4,6 & 23,1 & 11,8 & 2,8 & 3,0 & 47,1 & 104,5 \\
\hline Efeito & ns & ns & ns & L** & ns & ns & ns & ns \\
\hline C.V. (\%). & 6,4 & 8,1 & 10,3 & 9,0 & 9,7 & 7,4 & 16,5 & 13,9 \\
\hline
\end{tabular}

(1) $\mathrm{L}=$ Efeito linear por regressão polinomial. *, ** e ns: Significativos a 5 e $1 \%$ e não-significativo.

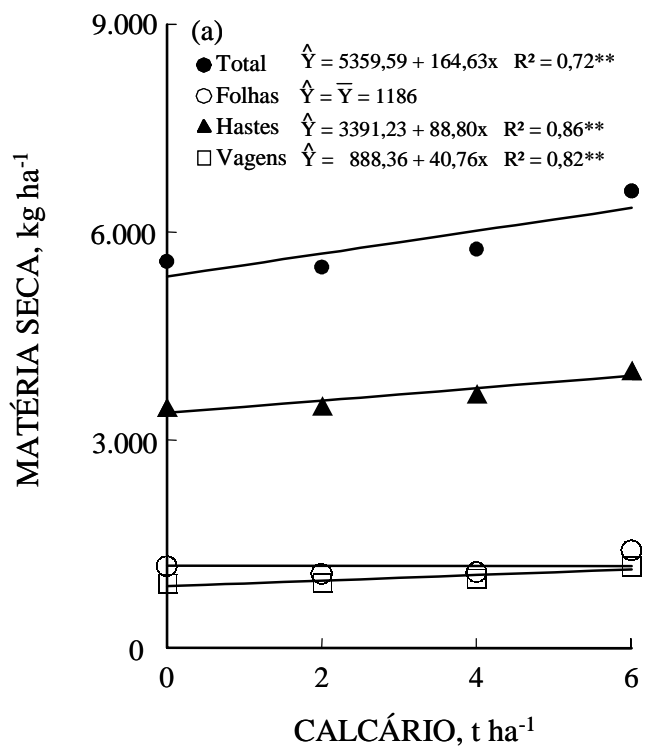

Figura 2. E feito de doses de calcário (a) e de gesso planta de soja. ** significativo a $1 \%$.

resultados podem levar à interpretação de que a calagem provocou perdas de K no solo ou diminuição de sua disponibilidade, dado o aumento dos teores de Ca e Mg. A redução dos teores de K no solo esteve associada aos níveis desse nutriente na parte aérea da soja, nos tratamentos onde o cal cário foi aplicado, mostrando que a diminuição do K trocável foi ocasionada pelo aumento da absorção do nutriente pela planta.

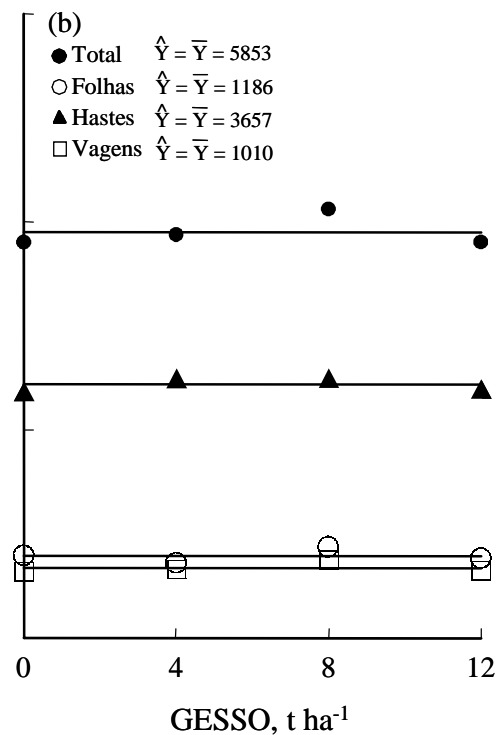

(b) na produção de matéria seca total e de partes da maior absorcão de Ca ocorreu com a maior disponibilidade deCa trocável no solo, proporcionada pela aplicação de calcário (Quadro 1). A calagem aumentou a absorção de $\mathrm{Mg}$ com o aumento do $\mathrm{Mg}$ trocável no solo (Quadro 1), com o uso de calcário dolomítico, concordando com os resultados obtidos por Mascarenhas et al. (1984). A maior absorção de $\mathrm{S}$ deve ter sido ocasionada pela li beração do sulfato adsorvido ou ainda por maior mineralização da 

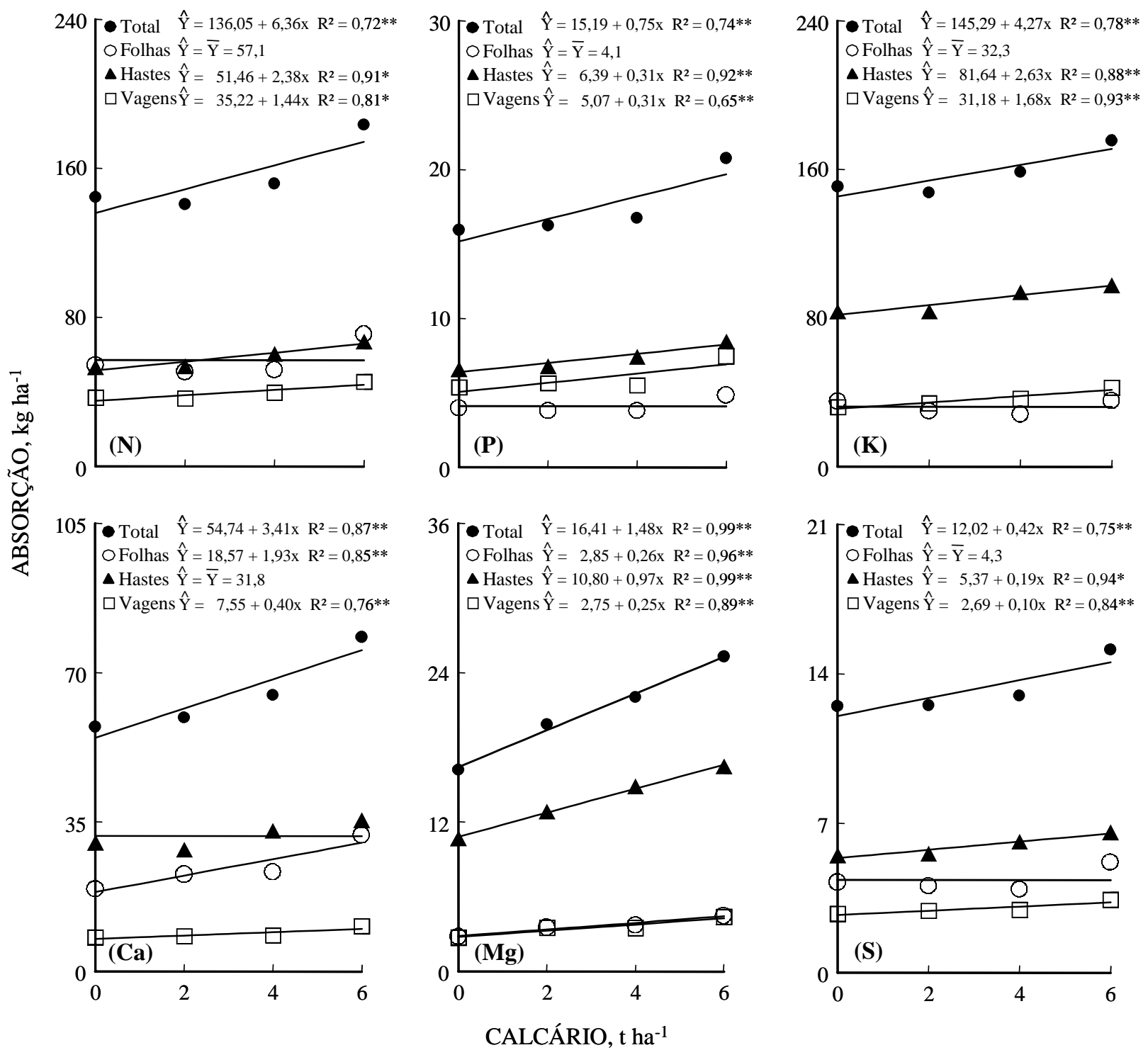

Figura 3. Efeito de doses de calcário na absorção de macronutrientes por diferentes partes da planta de soja. *, ** significativos a 5 e $1 \%$, respectivamente.

matéria orgânica, em decorrência da el evação do pH das camadas superficiais do solo com a calagem.

A aplicação de doses de gesso aumentou significativamente a absorção de Ca pelas fol has e hastes, o que resultou em maior extração do nutriente pela parte aérea, e de $S$ pelas hastes (Figura 4). Ressalta-se que o gesso é excel ente fonte desses dois nutrientes e quea sua aplicação também aumentou os teores de Ca trocável e de $\mathrm{S}-\mathrm{SO}_{4}{ }^{2-}$ do solo. E sses resultados mostram que o efeito do gesso sobre a nutrição de Ca e S da soja ocorre em longo prazo, quando sua aplicação é feita em doses elevadas na superfície, em sistema plantio direto. Não foram observadas alterações significativas na absorção de N, P, K e Mg pela cultura da soja com o uso de gesso.
A calagem aumentou significativamente a produção de grãos de soja, com resposta linear. De acordo com a equação ajustada $Y=2.715,18+43,45 x$ $\left(R^{2}=0,96\right)$, a máxima produção de grãos $\left(2.976 \mathrm{~kg} \mathrm{ha}^{-1}\right)$ foi obtida com a dose de $6 \mathrm{t} \mathrm{ha}^{-1} \mathrm{de}$ calcário. Baseando nos efeitos da calagem sobre as características químicas do solo (Quadro 1), observou-se que a máxima produção de soja ocorreu em solo com pH $\left(\mathrm{CaCl}_{2}\right)$ 5,5, 4,6 e 4,4 e saturação por bases de 63, 40 e 28\%, respectivamente, nas camadas de 0-5, 5-10 e 10-20 cm. Esses valores de pH e saturação por bases ficaram muito próximos dos obtidos por Caires et al. (2000) para a máxima produção de grãos, com a calagem na superfície, em sistema plantio direto. A aplicação de doses de gesso não influenciou, de forma significativa, a produção 

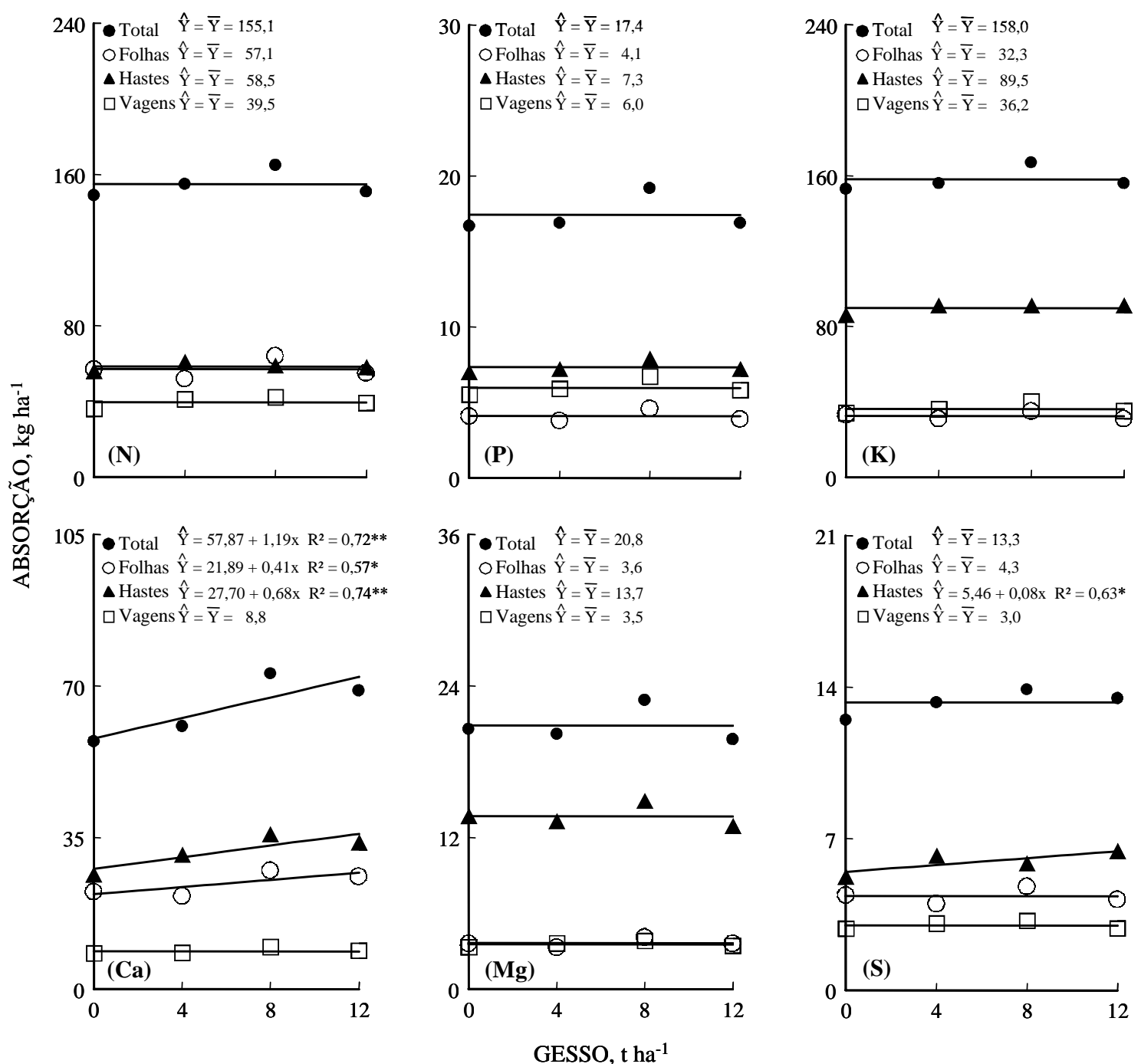

Figura 4. Efeito de doses de gesso na absorção de macronutrientes por diferentes partes da planta de soja. *, ** significativos a 5 e $1 \%$, respectivamente.

desoja. A produção de grãos foi de 2.848, 2.919, 2.725 e $2.890 \mathrm{~kg} \mathrm{ha}^{-1}$, respectivamente, para as doses de

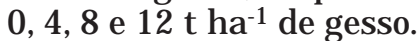

A análise de correlação entrea produção de grãos e os teores de nutrientes nas fol has de soja mostrou que o aumento da produção, pela calagem, deveu-se ao aumento da concentração de $\mathrm{Mg}$ nas folhas $(r=0,65)$ e à redução dos teores foliares de $Z n(r=$ $-0,53)$ e de $M n(r=-0,63)$. E mbora a calagem tenha aumentado a absorção de todos os macronutrientes pela cultura da soja, somente o aumento da extração de $\mathrm{Mg}$ correlacionou-se de forma positiva e significativa com a produção de grãos $(r=0,67)$. Esses resultados mostram que, na ausência de calagem, a concentração de $\mathrm{Mg}$ nas fol has $\left(2,4 \mathrm{~g} \mathrm{~kg}^{-1}\right)$ foi baixa e os teores foliares de $\mathrm{Zn}\left(54,3 \mathrm{mg} \mathrm{kg}^{-1}\right)$ e de $\mathrm{Mn}$ (127,3 $\mathrm{mg} \mathrm{kg}^{-1}$ ) foram altos (Quadro 3), o que está de acordo com os teores usados na interpretação de análise de fol has de soja, apresentados por Peck (1979). A absorção de Mg pela soja (Figura 3), na ausência de calagem (16 kg ha-1), também foi baixa, considerando os resultados obtidos por Bataglia \& Mascarenhas (1977) e por Cordeiro et al. (1979). Houve, portanto, deficiência de Mg etoxidez de Zn e Mn na cultura da soja, em condições de alta acidez do solo, mesmo sem a identificação de sintomas visuais. Esteéum indicativo de quea menor resposta da soja à calagem na superfície, em sistema plantio direto, observada em outros trabal hos (Caires et al., 1998, 1999; Pöttker \& Ben, 1998), pode estar relacionada com sol os ácidos com teores suficientes de Ca e Mg e concentrações não-tóxicas de Zn e Mn.

É importante ressaltar que o teor médio de $\mathrm{Mg}$ trocável no solo, na camada de $0-20 \mathrm{~cm}$, era de $9 \mathrm{mmol}_{\mathrm{c}} \mathrm{dm}^{-3}$ (Quadro 1) e, mesmo assim, houve resposta significativa da soja ao aumento do $\mathrm{Mg}$ do 
solo, em decorrência do uso de calcário dolomítico. Entretanto, não foi possível estabelecer uma faixa ideal de Mg trocável nosolo, uma vez que a resposta da soja à calagem foi linear. N otrabal ho de Rosolem et al. (1992), as produtividades máximas de soja ocorreram em teores de Mg trocável de 7 a $30 \mathrm{mmol}_{\mathrm{c}} \mathrm{dm}^{-3}$, dependendo do solo, cultivar, cal agem e adubação potássica.

A ausência de resposta da soja à aplicação de gesso, verificada em áreas de cultivos anuais preparadas convenci onal mente (Quaggio et al., 1993; Martins et al., 1998) e em sistema plantio direto (Oliveira \& Pavan, 1996; Caires et al., 1998, 1999), pode ser atribuída ao fato de o crescimento radicular da soja, na ausência de déficit hídrico, não ser influenciado pela redução da saturação por Al no subsolo.

\section{CONCLUSÕES}

1. A densidade e a superfície radicular da soja cultivada no sistema plantio direto não foram influenciadas pelas condições de acidez do solo. $\mathrm{O}$ aumento do Ca trocável de 8 para $18 \mathrm{mmol}_{\mathrm{C}} \mathrm{dm}^{-3} \mathrm{ea}$ redução do Al trocável de 11 para $5 \mathrm{mmol}_{\mathrm{c}} \mathrm{dm}^{-3}$ e da saturação por Al de 40 para $15 \%$, em profundidade (20-40 cm), não alteraram o crescimento radicular da soja, mostrando que, na ausência de déficit hídrico, a mel horia do subsolo ácido pode não proporcionar maior enraizamento da planta.

2. A correção da acidez do solo pela calagem na superfície, em sistema plantio direto, melhorou a nutrição da soja, aumentando a produção de grãos, em decorrência de maior disponibilidade e absorção de $\mathrm{Mg}$ e de redução dos teores foliares de Zn e Mn.

\section{LITE RATURA CITADA}

ARMINGER, W.H.; FOY, C.D.; FLEMING, A.L. \& CALDWELL, B.E. Differential tolerance of soybean varieties to an acid soil high in exchangeable aluminum. Agron. J., 60:67-70, 1968.

BATAGLIA, O.C. \& MASCARENHAS, H.A.A. Absorção de nutrientes pela soja. Campinas, I nstitutoAgronômico, 1977. 36p. (Boletim técnico, 41)

CAIRES, E.F. \& ROSOLEM, C.A. Root growth of peanut cultivars and soil acidity. In: WRIGHT, R.J .; BALIGAR, V.C. \& MURRMANN, R.P., eds. Plant-soil interactions at low pH. Dordrecht, Kluwer, 1991. p.239-243.

CAIRES, E.F.; CHUEIRI, W.A.; MADRUGA, E.F. \& FIGUEIREDO, A. Alterações de características químicas do solo e resposta da soja ao cal cário e gesso aplicados na superfície em sistema de cultivo sem preparo do solo. R. Bras. Ci. Solo, 22:27-34, 1998.
CAIRES, E.F.; FONSECA, A.F.; MENDES, J .; CHUEIRI, W.A. \& MADRUGA, E.F. Produção de milho, trigo e soja em função das alterações das características químicas do solo pela aplicação de cal cário e gesso na superfície, em sistema de plantio direto. R. Bras. Ci. Solo, 23:315-327, 1999.

CAIRES, E.F.; BANZATTO, D.A. \& FONSECA, A.F. Calagem na superfície em sistema plantio direto. R. Bras. Ci. Solo, 24:161-169, 2000.

CLARKSON, D.T. Interactions between aluminum and phosphorus on root surfaces cell wall material. Plant Soil, 27:347-355, 1967.

COLEMAN, N.T. \& THOMAS, G.W. The basic chemistry of soil acidity. In: PEARSON, R.W. \& ADAMS, F., eds. Soil acidity and liming. Madison, American Society of Agronomy, 1967. p.1-41.

CORDEIRO, D.S.; SFREDO, G.J .; BORKERT, C.M.; SARRUGE, J .R.; PALHANO, J.B. \& CAMPO, R.J . Calagem, adubação e nutrição mineral. In: EMPRESA BRASILEIRA DE PESQUISA AGROPECUÁRIA, Centro Nacional de Pesquisa de Soja. Ecologia, manejo e adubação da soja. Londrina, 1979. p.19-49. (Circular técnica, 2)

EMPRESA BRASILEIRA DE PESQUISA AGROPECUÁRIA EMBRAPA. Centro Nacional de Pesquisa de Solos. Manual de métodos de análise de solo. 2.ed. Rio de J aneiro, 1997. 212p.

FARINA, M.P.W. \& CHANNON, P. Acid - subsoil amelioration. II Gypsum effects on growth and subsoil chemical properties. Soil Sci. Soc. Am. J., 52:175-180, 1988.

FEHR， W.R.; CAVINESS, C.E.; BURMOOD, D.T. \& PENNINGTON, J.S. Stage of development description for soybeans (Glycinemax (L.) Merrill). Crop Sci., 11:929-931, 1971.

FOY, C.D.; FLEMING, A.L. \& ARMINGER, W.H. Aluminum tolerance of soybean varieties in relation to calcium nutrition. Agron. J ., 61:505-511, 1969.

FRANCHINI, J .C.; MALAVOLTA, E.; MIYAZAWA, M . \& PAVAN, M.A. Alterações químicas em solos ácidos após a aplicação de resíduos vegetais. R. Bras. Ci. Solo, 23:533-542, 1999.

HALLMARK, W.B. \& BARBER, S.A. Root growth and morphology, nutrient uptake and nutrient status of early grown soybeans as affected by soil P and K. Agron. J ., 76:209-212, 1984.

HANSON, W.D. \& KAMPRATH, E.J. Selection of aluminum tolerance in soybeans based on seedling-root growth. Agron. J., 71:581-586, 1979.

HORST, W.J .; ASHER, C.J .; CAKMAK, J .; SZULKIEWICZ, P. \& WISSE MEIER, A.H. Short-term response of soybean roots to aluminum. In: WRIGHT, J.R.; BALIGAR, V.C. \& MURRMANN, R.P., eds. Plant-soil interactions at low pH. Dordrecht, Kluwer, 1991. p.733-739.

MALAVOLTA, E.; VITTI, G.C. \& OLIVEIRA, S.A. Avaliação do estado nutricional das plantas: princípios e aplicações. 2.ed. Piracicaba, POTAFOS, 1997. 319p.

MARSCHNER, H. Mineral nutrition of higher plants. New York, Academic Press, 1986. 403p. 
MARTINS, O.C.; NOVAIS, R.F.;ALVAREZV., V.H.; BARROS, N.F. \& RIBEIRO, A.C. Respostas à aplicação de diferentes misturas de calcário e gesso em solos. II. Crescimento de raízes, absorção de nutrientes e produtividade da soja. $\mathrm{R}$. Ceres, 45:451-466, 1998.

MASCARENHAS, H.A.A.; MIYASAKA, S.; IGUE, T.; FREIRE, E.S. \& SORDI , G. Resposta da soja à calagem e à adubação mineral com fósforo e potássio em um Latossolo Roxo. Bragantia, 28:17-21, 1969.

MASCARENHAS, H.A.A.; BATAGLIA, O.C.; NAGAI, V. \& FALIVENE, S.M.P. Diferentes proporções de calcário calcítico e dolomítico no crescimento da soja em solos de cerrado. In: SEMINÁRIO NACIONAL DE PESQUISA DE SOJ A, 3., Campinas, 1984. Anais. Londrina, EMBRAPACentro Nacional de Pesquisa de Soja, 1984. p.852-863.

MCCORMICK, L.H. \& BORDEN, F.Y. Phosphate fixation by aluminum in plant roots. Soil Sci. Soc. Am. Proc., 36:799807, 1972.

MENOSSO, O.G.; COSTA, J.A.; ANGHINONI, I. \& BOHNEN, $H$. Tolerância de genótipos de soja ao alumínio em solução. Pesq. Agropec. Bras., 35:2157-2166, 2000.

MIYAZAWA, M.; PAVAN, M.A. \& SANTOS, J.C.F. Effects of addition of crop residues on the leaching of $\mathrm{Ca}$ and $\mathrm{Mg}$ in Oxysols. In: INTERNATIONAL SYMPOSIUM ON PLANTSOIL INTERACTIONS AT LOW pH, 4., Belo Horizonte, 1996. Abstracts. Belo Horizonte, Sociedade Brasileira de Ciência do Solo/ EMBRAPA-CPAC, 1996. p.8.

NOBLE, A.D. \& SUMNER, M.E. Calcium and Al interactions and soybean growth in nutrient solutions. Comm. Soil Sci. Plant Anal., 19:1119-1131, 1988.

NOBLE, A.D.; SUMNER, M.E.\& ALVA, A.K.The pH dependency of aluminum phytotoxicity alleviation by calcium sulfate. Soil Sci. Soc. Am. J ., 52:1398-1402, 1988.

OLIVEIRA, E.L. \& PAVAN, M.A. Control of soil acidity in notillage system for soybean production. Soil Till. Res., 38:4757, 1996.

PAVAN, M.A.; BINGHAM, F.T. \& PRATT, P.F. Toxicity of aluminum to coffee in Ultisols and Oxisols amended with $\mathrm{CaCO}_{3}$ and $\mathrm{CaSO}_{4}$. Soil Sci. Soc. Am.J ., 46:1201-1207, 1982.

PAVAN, M.A.; BLOCH, M.F.; ZEMPULSKI, H.C.; MIYAZAWA, M. \& ZOCOLER , D.C. Manual de análise química do soloe controle de qualidade. Londrina, Instituto Agronômico do Paraná, 1992. 38p. (Circular, 76)

PECK, T.R. Plant analysis for production agriculture. In: SOIL PLANT ANALYSIS WORKSHOP, 7., Bridgetown, 1979. Proceedings. Bridgetown, 1979. p.1-45.

PÖTTKER, D. \& BEN, J .R. Calagem para uma rotação de culturas no sistema de plantio direto. R. Bras. Ci. Solo, 22:675-684, 1998.

QUAGGIO, J.A.; MASCARENHAS, H.A.A. \& BATAGLIA, O.C. Resposta da soja à aplicação de doses crescentes de cal cário em Latossol o Roxo distrófico de cerrado. II - Efeito residual. R. Bras. Ci. Solo, 6:113-118, 1982.

QUAGGIO, J.A.; RAIJ , B. van; GALLO, P.B. \& MASCARENHAS, H.A.A. Respostas da soja à aplicação de cal cário e gesso e lixiviação de íons no perfil do solo. Pesq. Agropec. Bras., 28:375-383, 1993.
RAIJ , B. van. Gesso agrícola na mel horia do ambiente radicular no subsolo. São Paulo, Associação Nacional para Difusão de Adubos e Corretivos Agrícolas, 1988. 88p.

RAIJ, B. van \& QUAGGIO, J.A. Extractable phosphorus availability indexes as affected by liming. Comm. Soil Sci. Plant Anal., 21:1267-1276, 1990.

RAIJ, B. van; CAMARGO, A.P.; MASCARENHAS, H.A.A.; HIROCE, R.; FEITOSA, C.T.; NERY, C. \& LAUN, C.R.P. Efeito de níveis de calagem na produção de soja em solo de cerrado. R. Bras. Ci. Solo, 1:28-31, 1977.

RITCHEY, K.D.; SILVA, S.E. \& COSTA, V.F. Calcium deficiency in clayey B horizons of savannah Oxisols. Soil Sci., 133:378382, 1982

ROSOLEM, C.A. \& MARCELLO, C.S. Crescimento radicular e nutrição mineral da soja em função da calagem e adubação fosfatada. Sci. Agric., 55:448-455, 1998.

ROSOLEM, C.A.; MACHADO, J .R.; MAIA, I.G. \& NAKAGAWA, J. Respostas da soja ao magnésio do solo. R. Bras. Ci. Solo, 16:47-54, 1992.

ROSOLEM, C.A.;VALE, L.S.R.; GRASSI FILHO, H. \& MORAES, M.H. Sistema radicular e nutrição do milho em função da calagem e da compactação do solo. R. Bras. Ci. Solo, 18:491497, 1994

ROSOLEM, C.A.; BICUDO, S.J \& \& MARUBAYASHI, O.M. Soybean yield and root growth as affected by lime rate and quality. In: DATE, R.A., ed. Plant-soil interactions at low pH. Dordrecht, Kluwer, 1995. p.543-547.

SALET, R.L.; ANGHINONI, I.; FORNARI, T.G. \& KRAY, C.H. O alumínio é menos tóxico no sistema plantio direto. In: REUNIÃO SUL-BRASILEIRA DE CIÊNCIA DO SOLO, 1., Lages, 1996. Resumos Expandidos. Lages, Sociedade Brasileira de Ciência do Solo/Núcleo Regional Sul, 1996. p.72-74.

SARTAIN, J.B. \& KAMPRATH, E.J . Effect of liming a highly AIsatureted soil on the top and root growth and soybean nodulation. Agron. J ., 67:507-510, 1975.

SARTAIN, J.B. \& KAMPRATH, E.J . Aluminum tolerance of soybean cultivars based on root elongation in solution culture compared with growth in acid soil. Agron. J ., 70:1720, 1978.

SILVA, J .B.C.; NOVAIS, R.F. \& SEDIYAMA, C.S. Comportamento de genótipos de soja em sol o com alta saturação de alumínio. Pesq. Agropec. Bras., 19:287-298, 1984.

STOLF, R. Teoria e teste experimental de fórmulas de transformação dos dados de penetrômetro de impacto em resistência do solo. R. Bras. Ci. Solo, 15:229-235, 1991.

SUMNER, M.E. Amelioration of subsoil acidity with minimum disturbance. In: J AYAWARDANE, N.S. \& STEWART, B.A., eds. Subsoil management techniques. Athens, Lewis Publishers, 1995. p.147-185.

SUMNER, M.E.; SHAHANDEH, H.; BOUTON, J.\& HAMMEL, $J$. Amelioration of an acid soil prolife through deep liming an surface aplication of gypsum. Soil Sci. Soc. Am. J., 50:1254-1278, 1986.

TENNANT, D. A test of a modified line intersect method of estimating root length. J. Ecol., 63:995-1001, 1975.

TORMENA, C.A.; ROLOFF, G. \& SÁ, J.C.M. Propriedades físicas do sol o sob plantio direto influenciadas por calagem, preparo inicial e tráfego. R. Bras. Ci. Solo, 22:301-309, 1998. 